Polymer Journal, Vol. 38, No. 10, pp. 1061-1067 (2006)

(C) 2006 The Society of Polymer Science, Japan

\title{
Self-Assembly of Stereocomplex-Type Poly(lactic acid)
}

\author{
Yukiko FuruhashI, ${ }^{1, \dagger}$ Yoshiharu KIMURA, ${ }^{2}$ and Naoko YoshiE ${ }^{1, \dagger}$ \\ ${ }^{1}$ Institute of Industrial Science, The University of Tokyo, \\ 4-6-1 Komaba, Meguro-ku, Tokyo 153-8505, Japan \\ ${ }^{2}$ Department of Polymer Science and Engineering, Kyoto Institute of Technology, \\ Matsugasaki, Sakyo-ku, Kyoto 606-8585, Japan
}

(Received January 13, 2006; Accepted July 27, 2006; Published September 15, 2006)

\begin{abstract}
Enantiomeric poly(lactide)s were assembled by casting solutions of poly(L-lactic acid) and poly(D-lactic acid) with different drying process and annealing procedures. Crystallization in these films was studied by differential scanning calorimetric study and wide-angle X-ray diffraction. Stereocomplex crystallization occurred more predominantly than homo crystal during casting and annealing. Atomic force microscopic observation showed solutiongrown single crystal like structure on the substrate surface. We found that stereocomplex crystal formation was enhanced via homo crystal formation. On the basis of these findings, a mechanism is proposed for the crystallization of enantiomeric poly(lactic acid)s when they are cast from dilute solution. [doi:10.1295/polymj.PJ2005214]

KEY WORDS Poly(lactic acid) / Stereocomplex Crystal / Homo Crystal / Differential Scanning Calorimetry / X-Ray Diffraction / AFM Observation /
\end{abstract}

Poly(lactic acid) (PLA), made from natural plants such as corns, sugarcanes, or beets, attracts much attention not only as a biodegradable polymeric material, but also as a bioabsorbable material by its water degradability and intoxicity to human bodies, in addition, to the potential toughness derived by drawing processes. PLA, as illustrated in the formula: $\left[-\mathrm{C}^{*} \mathrm{H}\left(\mathrm{CH}_{3}\right)-\mathrm{CO}-\mathrm{O}-\right]_{\mathrm{n}}$, has an asymmetric carbon in its chemical structure, and therefore it can be classified into optically active poly(L-lactic acid) (PLLA) and poly(D-lactid acid) (PDLA). When the interaction of these stereo isomers is strong, it is well known that a stereocomplex-type crystal forms between these enantiomers, especially in an equimolecular mixture of PLLA and PDLA. ${ }^{1}$ A striking point which is different from homo crystal is the melting temperature of stereocomplex for $230^{\circ} \mathrm{C}$, which is $50^{\circ} \mathrm{C}$ higher than that of the homo crystal. This melting temperature is rather high among the biodegradable or bioabsorbable polyesters. Accordingly, stereocomplex-type PLA is now of great interest. However, stereocomplex formation is greatly affected by various conditions, and it is difficult to control the stereocomplexation in the materials. It has been reported that the crucial parameters affecting the stereocomplexation are the mixing ratio and the molecular weight of PLLA and PDLA. Stereocomplexation between PLLA and PDLA can occur in solution, in a solid (bulk) state from the melt, during polymerization, or during hydrolytic degradation..$^{2-8}$ In addition, it is interesting to investigate that how PLLA and PDLA act each other to form stereocomplex crystals in a molecular level. Serizawa et al. have reported that stepwise assembly of enantiomeric PLAs by quartz crystal microbalance (QCM) substrate and atomic force microscope (AFM). ${ }^{9}$ QCM analysis at each step showed stereocomplex formation on the substrate surface. AFM observation showed a dotted nanostructure of the assembly. They obtained the effects of assembly amount by increasing the PLA concentration, immersion time, and assembly temperature. They proposed that the racemic crystal formation was applied to the alternate deposition of certain structurally regulated polymers. In this study, we have demonstrated the stepwise organization of PLLA and PDLA from 1,4dioxane solutions by different drying procedures and different annealing temperatures. The organization was quantitatively monitored by differential scanning calorimetry, wide-angle X-ray diffractions, and atomic force microscopy.

\section{EXPERIMENTAL}

\section{Polymer Synthesis}

L-lactide and D-lactide were supplied by Purac Biochem Gorinchem (Holland) and Shimadzu Corp. (Kyoto), respectively, and were purified by recrystallization from ethyl acetate. Diethylene glycol monomethyl ether (DEGM) was purchased from Nacalai Tesque (Kyoto) and was distilled under a vacuum. Stannous 4-ethylhexanoate $\left(\mathrm{Sn}(\mathrm{Oct})_{2}\right)$ was purchased from Nacalai Tesque (Kyoto), distilled under reduced

\footnotetext{
${ }^{\dagger}$ To whom correspondence should be addressed (Tel: +81-3-5452-6309, Fax: +81-3-5452-6311, E-mail: yoshie@iis.u-tokyo.ac.jp).

${ }^{\dagger \dagger}$ Present address: Material Evaluation Group, Materials Engineering Center, R\&D Center, Tokyo Electric Power Company
} 
Table I. Characteristics of PLLA and PDLA used in this work

\begin{tabular}{ccc}
\hline & PLLA & PDLA \\
\hline${ }^{1} \mathrm{H}$ NMR $(\mathrm{ppm})$ & $5.15^{\mathrm{a}}$ & $5.14^{\mathrm{a}}$ \\
GPC & $1.50^{\mathrm{b}}$ & $1.55^{\mathrm{b}}$ \\
& $M_{\mathrm{w}}=17,000$ & $M_{\mathrm{w}}=23,000$ \\
DSC & $T_{\mathrm{g}}{ }^{\mathrm{c}}=50^{\circ} \mathrm{C}$ & $T_{\mathrm{g}}{ }^{\mathrm{c}}=53^{\circ} \mathrm{C}$ \\
& $T_{\mathrm{c}}{ }^{\mathrm{d}}=108^{\circ} \mathrm{C}$ & $T_{\mathrm{c}}{ }^{\mathrm{d}}=100^{\circ} \mathrm{C}$ \\
& $T_{\mathrm{m}}{ }^{\mathrm{e}}=169^{\circ} \mathrm{C}$ & $T_{\mathrm{m}}{ }^{\mathrm{e}}=159^{\circ} \mathrm{C}$ \\
\hline
\end{tabular}

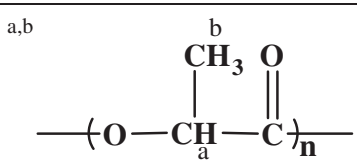

${ }^{\mathrm{c}}$ Glass transition temperature estimated by glass transition peak. ${ }^{\mathrm{d}}$ Crystallization temperature estimated by exothermic peak. ${ }^{e}$ Melting temperature estimated by endothermic peak.

pressure, and dissolved in distilled toluene at a concentration of $0.1 \mathrm{~g} / \mathrm{mL}$. Chloroform and diethyl ether were commercially supplied and distilled before use. PLLA and PDLA were prepared in accordance with previous studies. ${ }^{10}$ In brief, PLAs with a sharp molecular weight distribution were synthesized by ringopening polymerization of the corresponding lactide in the presence of DEGM. Five grams of lactide and $30 \mathrm{mg}$ of DEGM were charged into a $100 \mathrm{~mL}$ flask. After drying in vacuo for $3 \mathrm{~h}, 10 \mathrm{mg}$ of $\mathrm{Sn}(\mathrm{Oct})_{2}$ in toluene (10 mol \% relative to DEGM) was added under a nitrogen atmosphere. The flask was heated, and the mixture was stirred at $120^{\circ} \mathrm{C}$ for $7 \mathrm{~h}$. The reaction mixture was cooled and dissolved in $50 \mathrm{~mL}$ of chloroform, and the solution was poured into a large excess of diethyl ether for reprecipitation of polymer. The polymer was filtered and vacuum dried. Synthesized PLLA and PDLA were analyzed by gel permeation chromatography with a chloroform eluent using a polystyrene standard. Results of the gel permeation chromatography, ${ }^{1} \mathrm{H}$ NMR and differential scanning calorimetry (DSC) analysis are listed in Table I.

\section{Sample Preparations}

1,4-Dioxane for stepwise assembly was purchased from Nacalai Tesque (Kyoto) and used for casting without further purification. PLLA, PDLA, and mixture of PLLA and PDLA (1:1, noted as PLA) were dissolved in 1,4-dioxane at $70^{\circ} \mathrm{C}$ in an oil bath separately. The samples were heated in an oven at $100^{\circ} \mathrm{C}$ or $180^{\circ} \mathrm{C}$ for $30 \mathrm{~min}$. Annealing at $100^{\circ} \mathrm{C}$ induces the crystallization of homo crystal and/or stereocomplex crystal, while $180^{\circ} \mathrm{C}$ corresponds to the melting temperature of homo crystal. The sample prepared in this study was depicted in Figure 1.

Sample preparations are as follows:

Sample (1) (L): PLLA solution was deposited and only dried

\author{
Sample (2) (L100): Sample (1) \\ $\downarrow$ \\ annealed at $100^{\circ} \mathrm{C}$ \\ Sample (3) \\ (L100+D100): \\ Sample (2) \\ PDLA solution was de- \\ posited \\ annealed at $100^{\circ} \mathrm{C}$ \\ Sample (4) \\ Sample (3) \\ $(\mathrm{L} 100+\mathrm{D} 100+180)$ : \\ annealed at $180^{\circ} \mathrm{C}$ \\ Sample (5) (L+D): Sample (1) \\ PDLA solution was de- \\ posited \\ Sample (6)
(L+D100): \\ Sample (5) \\ annealed at $100^{\circ} \mathrm{C}$ \\ Sample (7) (LD): $\quad$ PLLA+PDLA (PLA) so- \\ lution was deposited and \\ only dried
}

Sample (8) (LD100): Sample (7)

annealed at $100{ }^{\circ} \mathrm{C}$

After each step, the samples were left to dry at least overnight at room temperature in order to dry completely. For X-ray and DSC samples, the specimens were allowed to dry on a Petri dish at room temperature.

\section{X-Ray Analysis}

Wide-angle X-ray diffraction (WAXD) scans were obtained at room temperature from a Rigaku RINT2100-FSL system with an X-ray generator using nickel-filtered $\mathrm{Cu} \mathrm{K} \alpha$ with wave-length of $0.1542 \mathrm{~nm}$, operating at $40 \mathrm{kV}$ and $20 \mathrm{~mA}$. For the scans, the $2 \theta$ range of 5 to $40^{\circ}$ at a scan rate of $2^{\circ} \mathrm{min}^{-1}$ was performed. The pattern can be divided into three areas, amorphous region over a wide range of $2 \theta=11^{\circ}$ to $30^{\circ}$, and noise region; the resulting crystallinity was estimated. Moreover, among the reflection peaks of crystalline region, the peak corresponds to homo and stereocomplex crystals exist. By calculating using a ratio of these ranges respectively, the crystallinity of homo and stereocomplex phases were estimated.

\section{Differential Scanning Calorimetry}

Thermal characteristics of the samples were measured using a Perkin-Elmer DSC Pyris 1 . Sealed aluminum sample pans containing 5-10 mg of materials were employed in all experiments. At the beginning of each experiment, the sample was heated to 

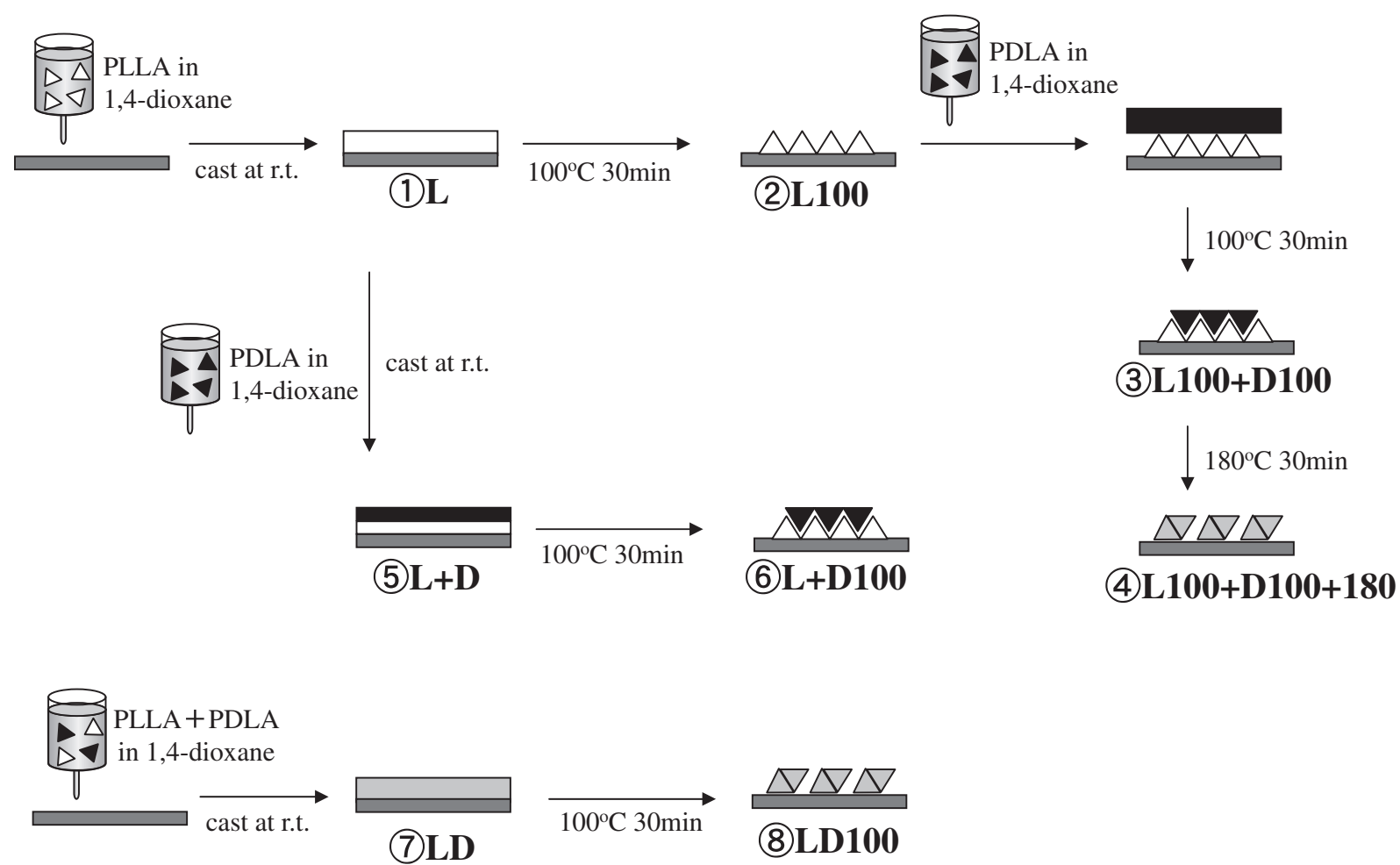

Figure 1. Schematic representation of sample preparations used in this study. The scheme was demonstrated that stepwise assembly of enantiomeric PLAs. A triangle indicates an isothermally crystallized enantiomeric PLA with annealing.

$250^{\circ} \mathrm{C}$ to observe 1 st heating scan, maintained for 5 min to eliminate its thermal history, and cooled to $30^{\circ} \mathrm{C}$ (cooling scan), then 2 nd heating was performed at a heating rate of $10^{\circ} \mathrm{C} \mathrm{min}^{-1}$. Melting temperature and crystallizing temperature was determined from the maximum of the endothermic peak and of the exothermic peak, respectively.

\section{Atomic Force Microscopy}

The AFM sample was prepared by spin-coating the solutions to silicon-wafer. The surface morphology of the samples was examined by AFM using a JSPM4200 (JEOL Inc.). Pyramid-shaped $\mathrm{Si}_{3} \mathrm{~N}_{4}$ tips, mounted on $160 \mu \mathrm{m}$ long micro-cantilevers, each with a spring constant of $0.1 \mathrm{~N} / \mathrm{m}$, were used for the tapping mode experiments in the air at ambient temperature. The 3D topographic data with high vertical resolution in selected areas with lateral sizes on the nanometric scale was acquired.

\section{RESULTS}

\section{DSC Measurements}

Figure 2 shows DSC thermograms with 1st heating, cooling, and 2nd heating, for the prepared PLA samples. The values of $T_{\mathrm{m}}, T_{\mathrm{c}}, \Delta H_{\mathrm{m}}$, and $\Delta H_{\mathrm{c}}$ obtained from the thermograms are summarized in Table II. The samples L and L100 showed an endothermic peak at about $155^{\circ} \mathrm{C}$ in the 1 st heating process; no peak in the cooling process; and the glass transition at $47^{\circ} \mathrm{C}$, a crystallizing exothermic peak at $98-100^{\circ} \mathrm{C}$, and endothermic peaks at 130 to $160{ }^{\circ} \mathrm{C}$ in the 2 nd heating process. Since the samples L and L100 contain no enantiomers, only homo crystallization is allowed. In the 2 nd heating process, there are small peaks at about $135-140^{\circ} \mathrm{C}$ and $157^{\circ} \mathrm{C}$ around the main endothermic peak at $151^{\circ} \mathrm{C}$. The higher one might correspond to the recrystallization of the melt. Accordingly, melting and crystallization temperatures of homo crystal of the sample prepared were about $150^{\circ} \mathrm{C}$ and $99^{\circ} \mathrm{C}$, respectively. Contrary to our expectations, the crystallization and melting peaks became smaller and broader with annealing at $100^{\circ} \mathrm{C}(\mathrm{L} 100)$, indicating that crystallization was suppressed and disordering of crystallite increases, with heating.

The DSC thermograms of the sample L100+D100 and $\mathrm{L} 100+\mathrm{D} 100+180$ indicated a large melting endothermic peak at $216^{\circ} \mathrm{C}$ for the 1 st heating process; a crystallizing exothermic peak at around 100 to $150^{\circ} \mathrm{C}$ for the cooling; and a melting endothermic peak at around $200^{\circ} \mathrm{C}$ for the 2 nd heating. Melting temperature of the samples showed about $210^{\circ} \mathrm{C}$, indicating that these systems possessed only stereocomplex crystals. The L100+D100 sample showed double crystallization peaks for the cooling and broad melting endotherm for the $2 \mathrm{nd}$ heating process. Although erasing thermal history in 1st heating, different crystallization exotherm of L100+D100 was observed 

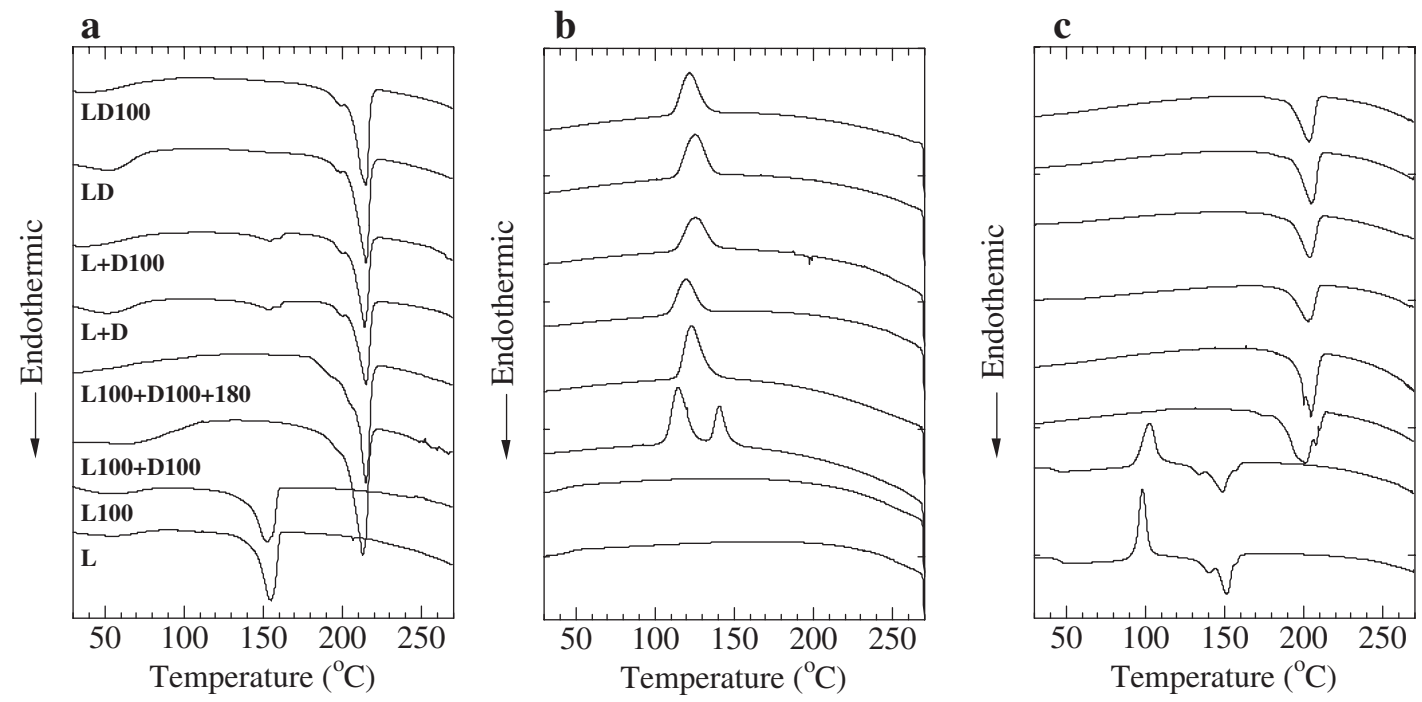

Figure 2. DSC thermograms of PLAs; (a) 1st heating process, (b) cooling process, and (c) 2nd heating process.

Table II. DSC results on PLA samples prepared in this study

\begin{tabular}{|c|c|c|c|c|c|c|c|c|c|c|c|c|}
\hline \multirow{2}{*}{ Sample } & \multicolumn{4}{|c|}{ 1st heating } & \multicolumn{2}{|c|}{ Cooling } & \multicolumn{6}{|c|}{ 2nd heating } \\
\hline & $T_{\mathrm{m}, \mathrm{H}}^{\mathrm{a}}$ & $\Delta H_{\mathrm{m}, \mathrm{H}}^{\mathrm{b}}$ & $T_{\mathrm{m}, \mathrm{S}} \mathrm{c}$ & $\Delta H_{\mathrm{m}, \mathrm{S}}{ }^{\mathrm{d}}$ & $T_{\mathrm{c}, \mathrm{S}}{ }^{\mathrm{e}}$ & $\Delta H_{\mathrm{c}, \mathrm{S}}{ }^{\mathrm{f}}$ & $T_{\mathrm{c}, \mathrm{H}^{\mathrm{g}}}$ & $\Delta H_{\mathrm{c}, \mathrm{H}}^{\mathrm{h}}$ & $T_{\mathrm{m}, \mathrm{H}}^{\mathrm{a}}$ & $\Delta H_{\mathrm{m}, \mathrm{H}}^{\mathrm{b}}$ & $T_{\mathrm{m}, \mathrm{S}} \mathrm{c}$ & $\Delta H_{\mathrm{m}, \mathrm{S}}^{\mathrm{d}}$ \\
\hline \multirow{2}{*}{$\mathrm{L}$} & \multirow{2}{*}{153} & \multirow{2}{*}{59} & & & & & \multirow{2}{*}{98} & \multirow{2}{*}{-34} & 140 & 3 & & \\
\hline & & & & & & & & & 152 & 41 & & \\
\hline \multirow{2}{*}{ L100 } & \multirow{2}{*}{155} & \multirow{2}{*}{55} & & & & & \multirow{2}{*}{103} & \multirow{2}{*}{-32} & 134 & 2 & & \\
\hline & & & & & & & & & 149 & 29 & & \\
\hline L100 & & & \multirow{2}{*}{213} & \multirow{2}{*}{74} & 115 & -31 & & & & & \multirow{2}{*}{201} & \multirow{2}{*}{46} \\
\hline +D100 & & & & & 141 & -15 & & & & & & \\
\hline L100 & & & & & & & & & & & & \\
\hline$+\mathrm{D} 100$ & & & 215 & 87 & 123 & -48 & & & & & 205 & 46 \\
\hline+180 & & & & & & & & & & & & \\
\hline $\mathrm{L}+\mathrm{D}$ & 154 & 11 & 215 & 60 & 120 & -37 & & & & & 203 & 35 \\
\hline $\mathrm{L}+\mathrm{D} 100$ & 155 & 8 & 214 & 66 & 125 & -42 & & & & & 204 & 40 \\
\hline LD & & & 215 & 69 & 125 & -45 & & & & & 205 & 34 \\
\hline LD100 & & & 215 & 73 & 122 & -44 & & & & & 203 & 34 \\
\hline
\end{tabular}

${ }^{\mathrm{a}}$ Melting temperature of homo crystal $\left({ }^{\circ} \mathrm{C}\right) .{ }^{\mathrm{b}}$ Enthalpy of fusion of homo crystal $(\mathrm{J} / \mathrm{g}) .{ }^{\mathrm{c}}$ Melting temperature of stereocomplex crystal $\left({ }^{\circ} \mathrm{C}\right)$. ${ }^{\mathrm{d}}$ Enthalpy of fusion for stereocomplex crystal $(\mathrm{J} / \mathrm{g}) .{ }^{\mathrm{e}}$ Crystallizing temperature of stereocomplex crystal $\left({ }^{\circ} \mathrm{C}\right) .{ }^{\mathrm{f}}$ Enthalpy of crystallization for stereocomplex crystal $(\mathrm{J} / \mathrm{g}) .{ }^{\mathrm{g}}$ Crystallizing temperature of homo crystal $\left({ }^{\circ} \mathrm{C}\right) .{ }^{\mathrm{h}}$ Enthalpy of crystallization for homo crystal $(\mathrm{J} / \mathrm{g})$.

compared to other samples. L100 sample shows the homo crystalline phase. By casting PDLA and annealing on L100 (L100+D100 sample), there seems to form different phases at the boundary region of PLLA and PDLA domains and the region of contacting to the silicon wafer, causing double crystallizing peaks of stereocomplex structure. It suggests that the interaction between silicon and PLA molecules are strong when once PLA molecules are annealed.

The $\mathrm{L}+\mathrm{D}$ and $\mathrm{L}+\mathrm{D} 100$ thermograms showed the large stereocomplex melting peak at $214^{\circ} \mathrm{C}$ with the small homo crystal melting peak at $160-165^{\circ} \mathrm{C}$ in the 1st heating process. However, 2nd heating, no homo crystal melting appeared. Only stereocomplex melting was observed.
The heating and cooling traces of LD and LD100 showed, a stereocomplex melting endothermic peak at $213^{\circ} \mathrm{C}$ during the 1 st heating procedures, a crystallizing peak at $125^{\circ} \mathrm{C}$ during cooling and a melting peak at $205^{\circ} \mathrm{C}$ during the 2 nd heating. The systems possessed only stereocomplex crystals, and no big difference occurred upon annealing at $100^{\circ} \mathrm{C}$, except for the disappearing of glass transition.

In summarizing the DSC results, the melting and crystallization of homo crystal occur around $155^{\circ} \mathrm{C}$ and $97^{\circ} \mathrm{C}$, respectively, while those of stereocomplex crystal occur around $210^{\circ} \mathrm{C}$ and $120^{\circ} \mathrm{C}$. Since $100^{\circ} \mathrm{C}$ is near to the crystallization temperature of homo crystals, annealing at that temperature induces homo crystallizing. However, the experimental results 
showed that stereocomplexation is enhanced rather than homo crystallization. The reason for this might be the fact that the homo crystallization is slower than stereocomplex crystallization. In fact, no homo crystallization appeared in the cooling process, but appeared in the 2 nd heating process in systems containing only PLLA.

In general, crystallinity contents of the specimens are determined by rating the enthalpy of melting and crystallizing peak to the reference melting enthalpy of the $100 \%$ crystalline polymer. Unfortunately, in this study, it is difficult to estimate the crystallinities of homo and stereocomplex crystals, because of the difficulty in determining the baseline when endothermic and exothermic peaks are overlapping. However, the peak areas of melting for homo and stereocomplex crystals can be reference indexes of crystallinities. The melting peaks of the 1st heating process are higher and the area are larger than these of the 2nd heating process, showing more uniform crystal was formed by just solvent-casting compared to the cooling and 2nd heating process. As mentioned above, interaction between PLA and substrate Si molecules are strong, inducing very high crystallinity. The melting endothermic peak showed maxima for L100+D100 or L100+ D100+180 samples compared to other samples.

\section{X-Ray Diffraction}

Two different crystal structures ( $\alpha$ - \& $\beta$-form) have been proposed for PLLA, based on X-ray diffraction patterns and conformational energy analysis. The salient features are as follows. The $\alpha$-form of PLLA is crystallized in a pseudo-orthorhombic unit cell with parameters for $a=1.07 \mathrm{~nm}, b=0.595 \mathrm{~nm}$, and $c$ (fiber axis) $=2.78 \mathrm{~nm} .{ }^{11,12}$ Two $10_{3}$ helices are contained in the unit cell of the PLLA crystal. The $\beta$-form appeared in solution-drawn and drawn fiber with higher drawing temperatures and/or higher hot-drawn ratios compared to $\alpha$-form. For this structure, an orthorhombic unit cell is proposed ( $a=1.03 \mathrm{~nm}, b=$ $1.82 \mathrm{~nm}$, and $c$ (fiber axis) $=0.900 \mathrm{~nm}$ ) containing six chains. ${ }^{12}$ Chain conformation of $\beta$-form is $3_{1}$ helix, in which is almost only fiber identity period is different from that of $\alpha$-form.

Okihara analyzed the stereocomplex crystal by $\mathrm{X}$-ray diffraction, electron diffraction and conformational energy analysis. ${ }^{13,14}$ This stereocomplex phase shows different crystal structure from that of homo crystal. The stereocomplex crystal system is triclinic $(P 1)$ with cell dimensions: $a=0.916 \mathrm{~nm}, b=0.916$ $\mathrm{nm}, c$ (chain axis) $=0.870 \mathrm{~nm}, \alpha=109.2^{\circ}, \beta=$ $109.2^{\circ}$, and $\gamma=109.8^{\circ}$. In the unit cell, PLLA and PDLA segment are contained as a pair and packed laterally in parallel fashion. Stereocomplex take a $3_{1}$ helical conformation, which is extended a little from

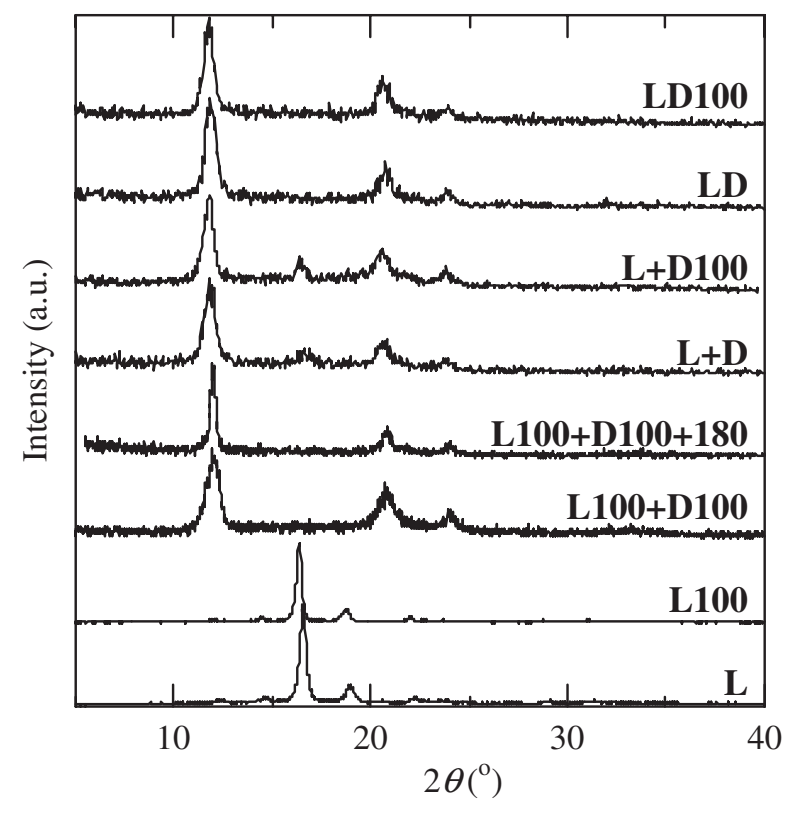

Figure 3. WAXD patterns of PLAs.

Table III. Estimated crystallinities obtained from X-ray diffraction scatterings of homo and stereocomplex crystals

\begin{tabular}{lrc}
\hline \multicolumn{1}{c}{ Sample } & $X_{\mathrm{c}, \mathrm{H}}{ }^{\mathrm{a}}$ & $X_{\mathrm{c}, \mathrm{S}}{ }^{\mathrm{b}}$ \\
\hline $\mathrm{L}$ & 92 & 0 \\
L100 & 88 & 0 \\
L100+D100 & 5 & 88 \\
L100+D100+180 & 0 & 91 \\
L+D & 10 & 70 \\
L+D100 & 15 & 77 \\
LD & 0 & 89 \\
LD100 & 0 & 92 \\
\hline
\end{tabular}

${ }^{\mathrm{a}}$ Crystallinity of homo crystal (\%). ${ }^{\mathrm{b}}$ Crystallinity of stereocomplex crystal (\%).

$10_{3}$ helix in the homo crystal with the $\alpha$-form.

WAXD patterns of the prepared PLA samples are shown in Figure 3. For PLLA sample (L and L100), (110) and (200) reflection at $17^{\circ}$ is clearly observed, which can be assigned to $\alpha$-form for dried PLLA and annealed PLLA. ${ }^{11,12}$ No significant change was observed between L and L100, although annealed at homo crystallizing temperature. The pattern was divided into a broad peak at $2 \theta=9-30^{\circ}$ from the amorphous phase and narrow peaks from the crystals. The crystallinity was estimated by dividing the crystalline peaks by the overall region. Among the reflection peaks of crystalline region, the peak corresponds to homo and stereocomplex crystals exist. From the ratio of these ranges, the crystallinities of homo and stereocomplex phases were estimated. The results are shown in Table III. Almost no amorphous reflection appeared and showed quite high crystallinities about $90 \%$ in every sample compared to industrial products. 

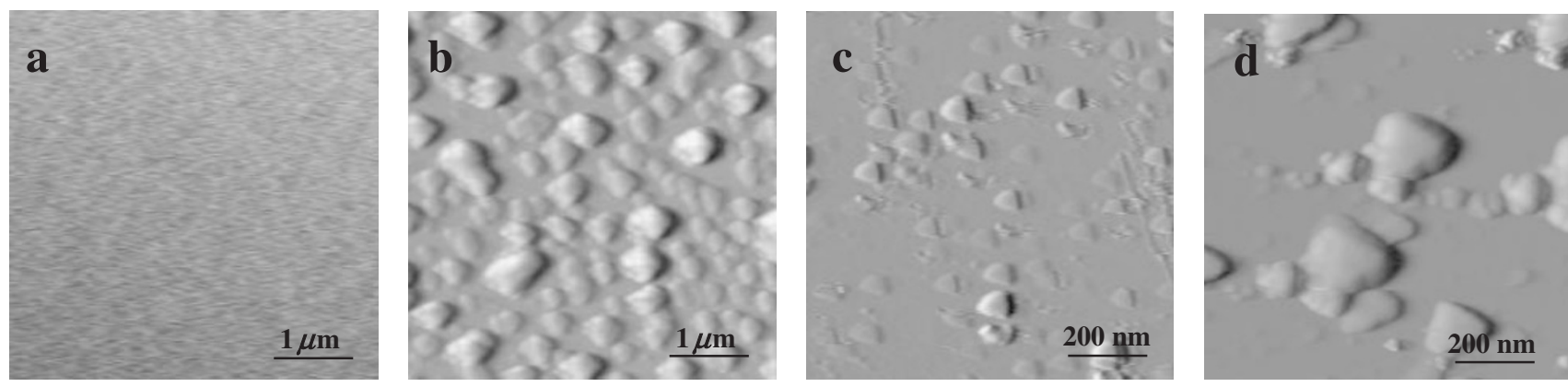

Figure 4. AFM images of PLAs with the sample; (a) L, (b) L100, (c) L100+D100, and (d) L100+D100+180.

The molecular weight of the polymers that were prepared in this study is low, indicating that the enhancement of crystallization occurs with these short molecular chains, even when only dried.

L100+D100 and L100+D100+180 showed almost the same WAXD patterns, with the reflections at $2 \theta=$ $12^{\circ}$ of (100), (010), and (-110), $21^{\circ}$ of (110), (-120), and $(-210)$, and $24^{\circ}$ of (200), (020), and (-220). All of them are assigned to the stereocomplex phase, and no reflections correspond to homo crystal phase appeared. The reflections became sharper with annealing at $180^{\circ} \mathrm{C}$, indicating that the stereocomplex crystallization proceeds at that temperature.

The $\mathrm{L}+\mathrm{D}$ and $\mathrm{L}+\mathrm{D} 100$ profiles showed small homo crystal reflections in addition to large stereocomplex crystal reflections. This result is coincident with the DSC measurements (Figure 2). Upon annealing at $100^{\circ} \mathrm{C}$, the homo crystal reflection became larger and stereocomplex reflection becomes sharper, indicating that both homo and stereocomplex crystallization is enhanced with annealing.

LD and LD100 showed almost the same patterns as L100+D100 and L100+D100+180 indicating the presence of only stereocomplex crystals. It implies that only mixing the PLLA and PDLA in solution state forms stereocomplex crystal.

\section{AFM Observations}

Figure 4a shows the AFM image of PLLA cast with no annealing. The AFM image showed no specific feature. With annealing at $100^{\circ} \mathrm{C}$ for $30 \mathrm{~min}$ (Figure $4 \mathrm{~b})$, which allowed the crystallization of homo crystals, there appeared lozenge-shaped platelets. The size of the platelet was $c a .600 \mathrm{~nm}$ in the long direction, and $c a .300 \mathrm{~nm}$ in the short direction. The thickness of each crystal was $7 \mathrm{~nm}$, measured from edge profiles. The solution-grown PLLA single crystal also showed lozenge-shaped, by isothermal crystallization in acetonitrile solution ${ }^{15}$ or $p$-xylene. ${ }^{16}$

Figure 4c shows L100+D100 AFM image. The triangular shapes were observed with dimensions of about $70 \mathrm{~nm}$, smaller than the sample L100. Similar equilateral-triangle-shaped single crystal was observ- ed by TEM and AFM in the stereocomplex crystal by Okihara et al. ${ }^{13}$ and Cartier et al. ${ }^{17}$

Figure 4d shows the AFM image of L100+D100+ 180 sample, which is the annealed sample of $\mathrm{L} 100+\mathrm{D} 100$ (Figure $4 \mathrm{c}$ ) at $180^{\circ} \mathrm{C}$ for $30 \mathrm{~min}$. The dimensions of the triangular shapes were about $250 \mathrm{~nm}$. Bigger crystals were observed compared to L100+ D100, indicating that crystallization proceeds during annealing at $180^{\circ} \mathrm{C}$. The triangular shapes with edges less certain than in Figure 4c were observed, suggesting melting of the stereocomplex crystal starts at $180^{\circ} \mathrm{C}$.

Homo crystals (Figure 4b) were bigger than stereocomplex crystals (Figures $4 c$ and $4 d$ ). It is commonly suggested that the rate of homo crystallization of polymers is higher than that of stereocomplex crystallization. However, as discussed in the DSC results, the homo crystallization of PLA is much slower than the stereocomplex crystallization. The bigger homo crystallite size might indicate that stereocomplex-type crystals are formed from homo crystals.

These pictures indicate that crystallization on a substrate with solid state and that of grown from dilute solution occurs almost the same outlines, although the sizes are different, which few microns order and submicron order for this substrate-on bulk state crystallization and solid state crystallization, respectively.

\section{DISCUSSION}

1,4-Dioxane was selected as the solvent for casting because it has poor solubility upon PLAs. If we use the good solvent such as chloroform, the mixture of PLLA and PDLA may have occurred even when PDLA was deposited on the cast-dried PLLA. Accordingly, all samples show same results, showing only stereocomplex crystalline phases, no homo phases. By using 1,4-dioxane, the solubility was poor compared with chloroform. The heating is needed for dissolving the PLAs with 1,4-dioxane. Accordingly, using 1,4-dioxane as a solvent, only depositing on the enantiomer surface, no complete mixing occurred between PLLA and PDLA. However, stereocomplex 

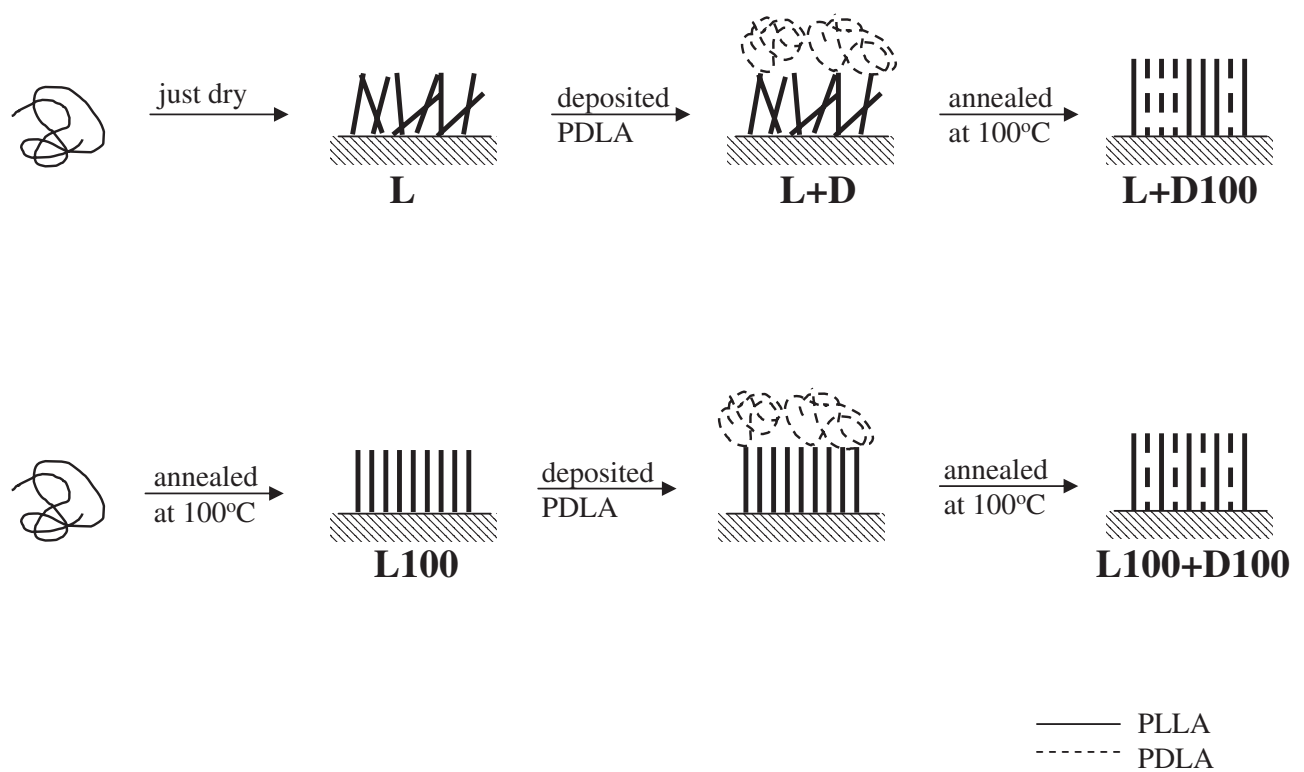

Figure 5. Schematic representation of PLA crystallite formation between PLLA and PDLA pairs cast from solution.

crystallization took place faster than homo crystallization in this study. It has been reported that the molecular weight plays an important role to the stereocomplex formation; either PLLA or PDLA has a low molecular weight, e.g. 5,000, meanwhile, crystallites of PLLA or PDLA homo crystal were predominantly forms when the molecular weight of both polymers are high, e.g., 100,000. ${ }^{3}$ The molecular weights synthesized in this study were about 20,000, so it depends on other conditions whether homo or stereocomplex crystallization occurred. In this case, the nucleation and growth of the stereocomplex crystallites appear to come to completion readily, even when solvent evaporation within a short period of time. Stereocomplex formation between the enantiomeric PLAs was based only on van der Waals contact between PLAs. This means that this type of stereocomplex crystal formation between structurally well-defined polymers could be applied to alternate deposition.

L100+D100 sample contained only stereocomplex crystal, while L+D100 sample contained almost stereocomplex crystal but also homo crystal. This indicates that it is easy to form stereocomplex crystals when once homo crystals were formed. It is suggested that when PLLA was only dried, the molecular chains align random on the substrate, while PLLA sample was dried and annealed, the molecular chains align perpendicular to the surface, as depicted in Figure 5. When PDLA was deposited on these perpendicularly aligned PLLA samples, the PDLA chains were inserted alternatively to the aligned PLLA. Meanwhile, it is difficult to insert PDLA chains on the randomly aligned PLLA chains, which leads to also the homo crystallization.
Acknowledgment. This work was financially supported by the Ogasawara Foundation for the Promotion of Science and Engineering.

\section{REFERENCES}

1. Y. Ikada, K. Jamshidi, H. Tsuji, and S.-H. Hyon, Macromolecules, 20, 906 (1987).

2. H. Tsuji, F. Horii, S.-H. Hyon, and Y. Ikada, Macromolecules, 24, 2719 (1991).

3. H. Tsuji, S.-H. Hyon, and Y. Ikada, Macromolecules, 24, 5651 (1991).

4. H. Tsuji, S.-H. Hyon, and Y. Ikada, Macromolecules, 24, 5657 (1991).

5. H. Tsuji, S.-H. Hyon, and Y. Ikada, Macromolecules, 25, 2940 (1992).

6. H. Tsuji and Y. Ikada, Macromolecules, 25, 5719 (1992).

7. H. Tsuji, F. Horii, M. Nakagawa, Y. Ikada, H. Odani, and R. Kitamaru, Macromolecules, 25, 4114 (1992).

8. H. Tsuji and Y. Ikada, Macromolecules, 26, 6918 (1993).

9. T. Serizawa, H. Yamashita, T. Fujiwara, Y. Kimura, and M. Akashi, Macromolecules, 34, 1996 (2001).

10. W. Amass, A. Amass, and B. Tighe, Polym. Int., 27, 89 (1998).

11. P. De Santis and A. J. Kovacs, Biopolymers, 6, 299 (1968).

12. W. Hoogsteen, A. R. Postema, A. J. Pennings, G. ten Brinke, and P. Zugenmaier, Macromolecules, 23, 634 (1990).

13. T. Okihara, A. Kawaguchi, H. Tsuji, S.-H. Hyon, Y. Ikada, and K. Katayama, Bull. Inst. Chem. Res., Kyoto Univ., 66, 271 (1988).

14. T. Okihara, M. Tsuji, A. Kawaguchi, and K. Katayama, J. Macromol. Sci., Part B: Phys., 30, 119 (1991).

15. T. Miyata and T. Masuko, Polymer, 38, 4003 (1997).

16. T. Iwata and Y. Doi, Macromolecules, 31, 2461 (1998).

17. L. Cartier, T. Okihara, and B. Lotz, Macromolecules, 30, 6313 (1997). 